\title{
Retrospective study of histological features of acute rejection in renal allografts and comparison with circulating $T$ cell populations
}

\author{
J WYATT, SR APARICIO, P GUILLOU \\ From the University Departments of Pathology and Surgery, St James's University Hospital, Leeds
}

SUMMARY The histological severity of acute rejection in renal allografts was determined for 39 rejection episodes in 30 renal transplant recipients. Data were compared with the peripheral blood $\mathrm{T}$ cell subset ratios measured before and at the onset of the rejection episode. $\mathrm{T}$ cell subset ratios showed no correlation with the histological severity of rejection, nor with the reversibility of the rejection episode. The grade of histological rejection on biopsy was predictive of graft survival. We conclude that renal biopsy remains the best method for determining the severity and outcome of acute allograft rejection episodes.

Renal biopsy has an established role in the diagnosis of rejection in renal transplant recipients. The histological severity of rejection predicts the response of the rejection episode to treatment and may have prognostic significance for long term graft function. ${ }^{1-4}$

Changes in circulating lymphocyte populations in transplant recipients were first described in $1976,{ }^{5}$ and, more recently, monoclonal antibodies to specific lymphocyte subsets have been used to monitor their fluctuations during rejection. A consistent pattern of change may provide a rapid diagnostic test for rejection. Several workers have suggested that the ratio of helper to suppressor/ cytotoxic lymphocytes increases before the onset of rejection and falls as the process is reversed. ${ }^{-9}$ Other centres, however, have been unable to confirm this relation. ${ }^{10-13}$

The aims of this study were to examine the relation between the histological changes in rejecting renal allografts and measurements of peripheral blood $T$ cell subsets before and during rejection. The prognostic value of the two were compared.

\section{Patients and methods}

Data on 30 recipients of renal transplants performed in the Regional Transplant Centre at St James's Hospital, Leeds, between September 1982 and September 1983 were studied. All patients experienced acute rejection episodes, during which peripheral blood $\mathrm{T}$ cell subset measurements were made. There were 21 men and nine women, with a mean age of 35.4 (range 15-60) years. All grafts were of cadaveric origin. Standard immunosuppression with steroids and azathioprine was used according to a previously described regimen. ${ }^{14}$ Acute rejection episodes were treated with increased doses of corticosteroids, up to $5 \mathrm{~g}$ methyl prednisolone over five days. The date of onset of rejection was taken as the day of first increase in a previously falling or stable serum creatinine concentration, accompanied by clinical signs of rejection. A clear date of onset was defined by these criteria in 23 of 39 rejection episodes. The follow up interval for graft survival is between 16 and 28 months.

HISTOLOGICAL STUDIES

Material available for histology consisted of open wedge biopsy (30) and nephrectomy specimens (9) obtained during the rejection episode. More than one specimen was received from eight patients; these were regarded as separate rejection events for the purposes of this study. At least five sections were studied in each case. The recently described method of Matas et al' was slightly modified and used to assess the histological severity of acute rejection.

This method categorises separately the degree of vascular rejection and intensity of tubulointerstitial inflammation. Acute vascular rejection is characterised by endothelial swelling and infiltration by mononuclear cells; when this change was seen in more than half the arteries and arterioles in the 
biopsy it was graded as moderate $(++)$, and when in less than half as mild $(+)$. Severe $(+++)$ acute vascular rejection was diagnosed when any of the vessels showed necrotising vasculitis, fibrinoid necrosis, or fibrin-platelet thrombosis.

Acute tubulointerstitial rejection shows the features of an interstitial mononuclear infiltrate, interstitial oe dema, and tubular damage. This was graded on a scale of mild $(+)$ to severe $(+++)$, depending on the intensity of inflammation and whether the changes were focal $(+)$ or diffuse $(+++)$.

This method also includes a system for grading chronic vascular and chronic tubulointerstitial rejection, but as these are not relevant to the present study they are not described here.

The degree of rejection was determined for all wedge biopsies without knowledge of the clinical outcome, and all specimens were assigned a separate grade of acute vascular and acute tubulointerstitial rejection.

\section{IMMUNOLOGICAL STUDIES}

Peripheral blood T lymphocytes had been estimated in these patients three times a week during their stay in hospital and weekly after discharge. Blood samples from patients in hospital were all obtained between 9 and $10 \mathrm{am}$. Lymphocytes were isolated from heparinised blood on a Ficoll-Hypaque gradient, washed, and stained with commercially available monoclonal antibodies (Orthoclone) to total mature $T$ cells (OKT3), helper T cells (OKT4), and suppressor/cytotoxic T cells (OKT8), according to a previously described technique. ${ }^{15}$ The ratio T4:T8 was derived and used for comparison with histological data because this ratio is claimed to be a more reliable indicator of rejection than absolute $\mathrm{T}$ cell numbers. ${ }^{8}$

The subset ratios in blood samples, collected within a day of biopsy or nephrectomy, were available in 26 cases, and samples from four to six days previously were available in 29 cases.

\section{Results}

\section{HISTOLOGY}

Histological evidence of acute rejection was present in all specimens. Two of the biopsies $(7.4 \%)$ contained fewer than four vessels and were therefore inadequate for quantification of acute vascular rejection. These were assigned to acute tubulointerstitial rejection grades only. Table 1 shows the number of cases in each diagnostic group.

Biopsy or nephrectomy was performed at variable times (1-10 days) after the onset of rejection. Fig. 1 shows the relation between the histological grade (combined acute vascular and acute tubulointersti- tial rejection) and the time between the first rise in creatinine and biopsy or nephrectomy for those patients in whom the date of onset of rejection could be reliably determined. There was no tendency for later samples to show greater severity, which suggests that the severity of a given rejection episode remains constant and is mild or severe from the outset.

Twenty of the biopsies were obtained either during treatment for acute rejection or less than six days after finishing treatment. A further 10 were obtained at least seven days after completing acute antirejection treatment. Table 2 shows the relation with histological grade. The presence of severe histological rejection during a course of steroids implies that they did not modify the morphological expression of rejection in those patients. In addition, the prognostic value of biopsy was not affected by concurrent steroid treatment for the rejection episode.

\section{IMMUNOLOGY}

Immunofluorescence using the OKT series of monoclonal antibodies gave measurements of $\mathrm{T} 4$ positive and T8 positive cells, which agreed with the total percentage of $\mathrm{T} 3$ positive cells in most cases. In five instances ( $8 \%$ of measurements) the sum of $\mathrm{T} 4$ plus T8 positive cells was significantly higher $(>15 \%$ higher) than the total number of $\mathrm{T} 3$ positive cells, which implies the presence of phenotypically atypical $\mathrm{T}$ cells ( $\mathrm{T} 4$ and $\mathrm{T} 8$ positive or $\mathrm{T} 3$ negative cells). In these cases the T4:T8 ratio was invalidated and not used for comparison with the histological appearances of the graft. This phenomenon was not consistently associated with high dosage steroid treatment. T4:T8 ratios fluctuated considerably in individual patients after transplantion. No consistent pattern was seen before or during a rejection episode, nor did the use of steroids have a predictable effect on the subset ratios during such an episode.

\section{COMPARISON OF HISTOLOGICAL APPEARANCES} WITH T CELL SUBSET RATIOS

$T$ cell subset ratios estimated within a day of biopsy or nephrectomy in 26 cases were compared with the severity of acute vascular and acute tubulointerstitial rejection (Fig. 2); the circulating $\mathrm{T}$ cell subset ratios bore no relation to the intensity of the rejection process within the graft, as seen histologically.

In view of reports that circulating $T$ cell subset changes may preceed the clinical appearance of rejection by several days, we compared the $T$ cell subsets measured four to six days before biopsy or nephrectomy ( 29 cases) with the histological severity of acute vascular and acute tubulointerstitial 
Table 1 No of cases with each histological grade of rejection

\begin{tabular}{llllr}
\hline & \multicolumn{2}{l}{ Grade of rejection } & & \\
\cline { 2 - 5 } & - & + & ++ & +++ \\
\hline $\begin{array}{llll}\text { Acute vascular rejection } \\
\text { Acute tubulointerstitial rejection }\end{array}$ & 5 & 14 & 9 & 9 \\
\hline & $\begin{array}{l}\text { Mild } \\
(1-2+)\end{array}$ & 11 & 12 & $\begin{array}{c}\text { Moderate } \\
(3-4+)\end{array}$ \\
\cline { 2 - 5 } $\begin{array}{l}\text { Combined (acute vascular and acute } \\
\text { tubulointerstitial rejection) }\end{array}$ & 13 & $15+6$ & 11 \\
\hline
\end{tabular}

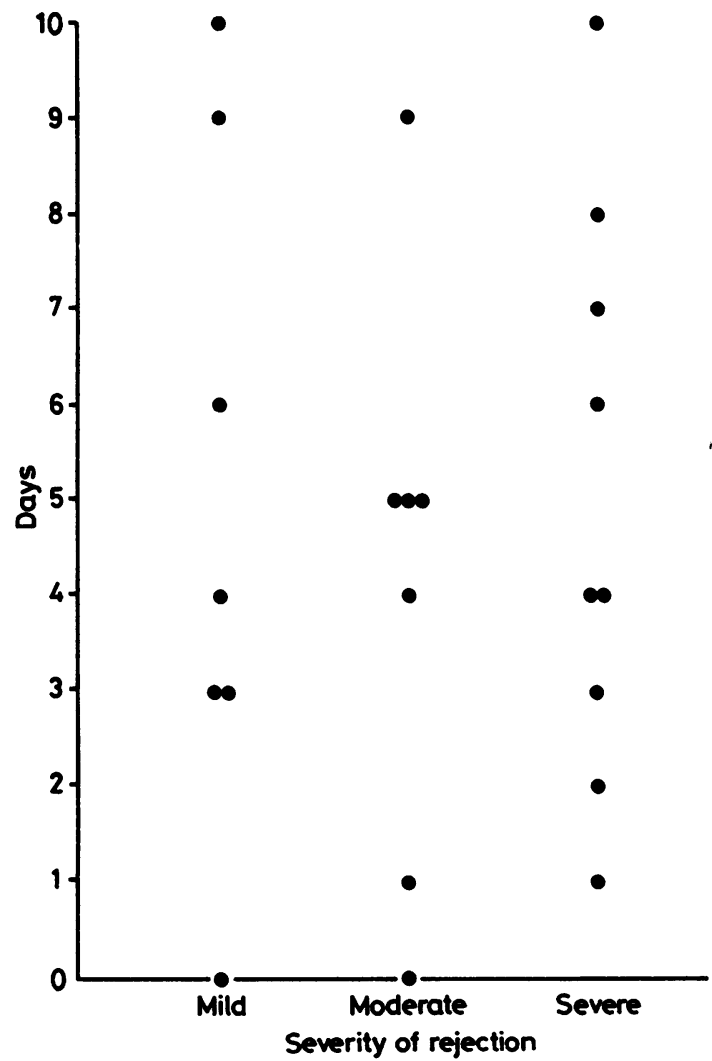

Fig. 1 Severity of rejection $v$ number of days between onset of rejection and biopsy or nephrectomy. rejection (Fig. 3). Circulating $\mathrm{T}$ cell subsets did not forecast the intensity of histological rejection.

\section{PROGNOSTIC VALUE}

The prognostic value of biopsy during rejection is established, and our findings relating the outcome of the transplant to the severity of rejection seen on biopsy are comparable with those of other authors ${ }^{1}$ (Table 3). In five patients there were two biopsies showing different degrees of rejection, but only the more severe grade is included in Table 3. One patient with severe rejection on biopsy had good long term function. She was later found on isotope scanning to have an area of infarction in an otherwise functioning graft. The other four biopsies showing severe rejection were followed by nephrectomy, after an average of three weeks (range one to eight weeks). The four nephrectomies following mild or moderate acute rejection biopsies were performed for chronic rejection (three) or cytomegalovirus infection (one). Morphological features of cytomegalovirus infection could not be identified in this kidney. Eleven patients with mild or moderate rejection on biopsy had functioning grafts after 16-28 months. In two of these patients with moderate rejection there was chronic impairment of graft function with a serum creatinine concentration greater than $200 \mu \mathrm{mol} / \mathrm{l}$.

T cell subset ratios estimated before transplantion, four to six days before a rejection episode, or at the onset of a rejection episode (Fig. 4) showed no prognostic value with regard to either reversibility of the rejection episodes or long term graft survival.

Table 2 Histological grade of rejection $v$ steroid treatment of rejection episode

\begin{tabular}{lll}
\hline Grade of rejection & Steroids $<6$ days before biopsy & No steroids for $>6$ days before biopsy \\
\hline Mild & 6 & 3 \\
Moderate & 5 & 5 \\
Severe & 9 & 2 \\
\hline
\end{tabular}



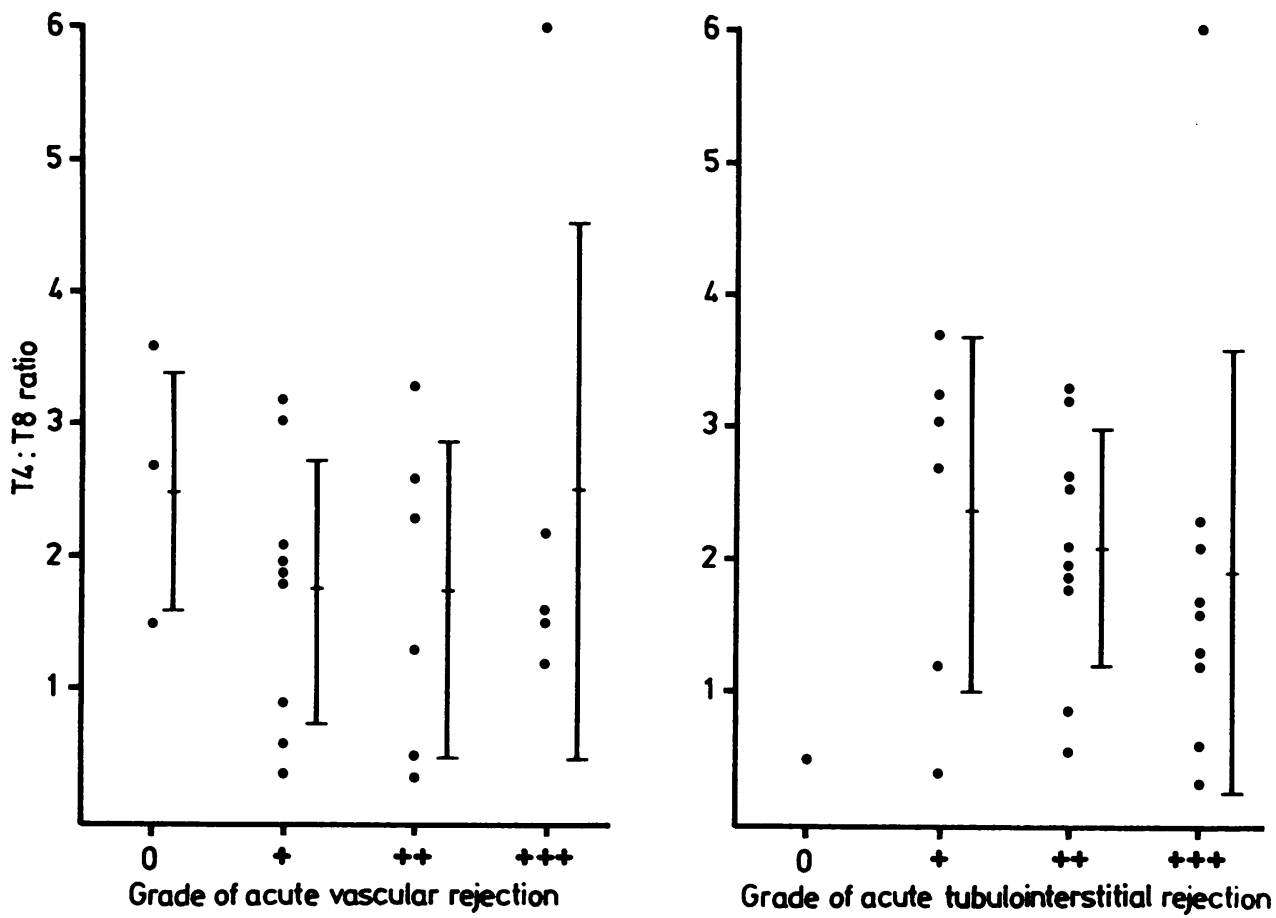

Fig. 2 T4:T8 ratio measured within one day of biopsy or nephrectomy $v$ histological grade of rejection. Bar shows mean ( $\pm 1 \mathrm{SD})$.
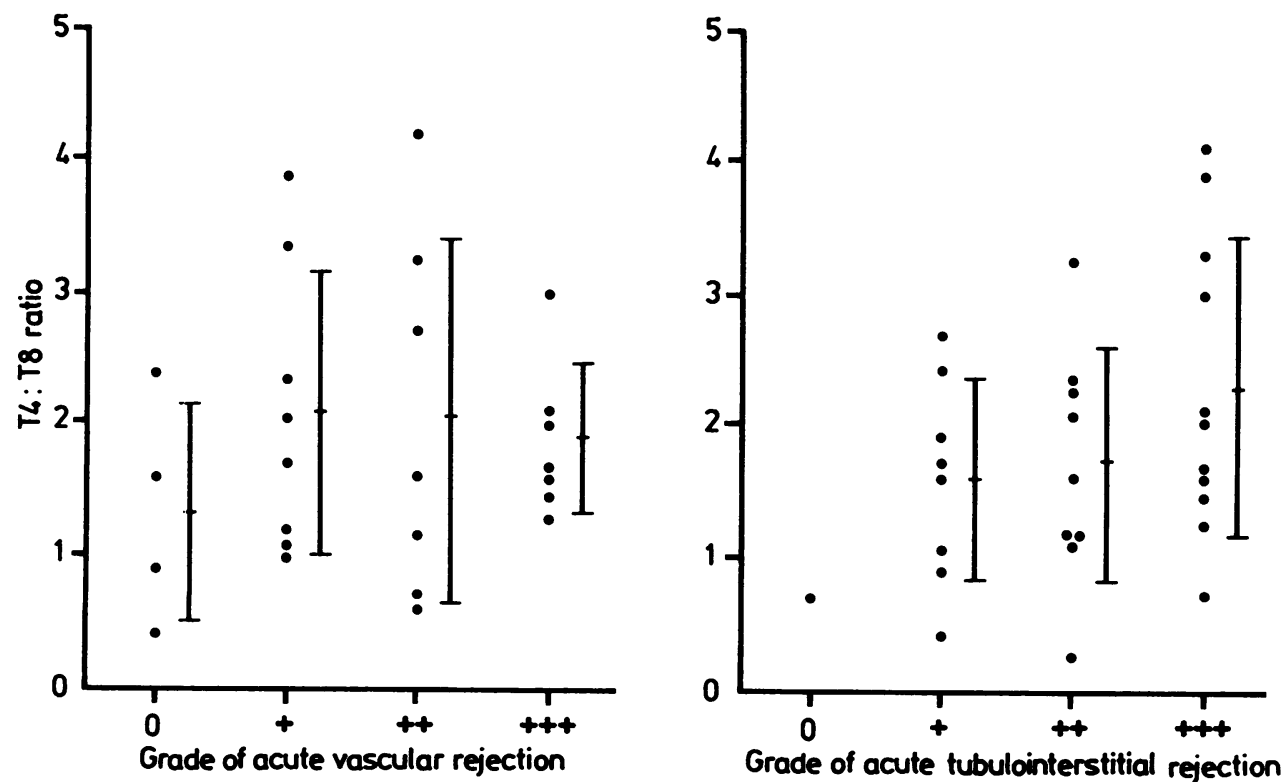

Fig. 3 T4:T8 ratio measured four to six days before biopsy or nephrectomy $v$ histological grade of rejection. Bar shows mean ( $\pm 1 \mathrm{SD})$. 
Table 3 Outcome of transplant $v$ histological grade of rejection on biopsy in 22 patients

\begin{tabular}{llll}
\hline & Severity of rejection & Severe \\
\cline { 2 - 4 } & Mild & Moderate & 1 \\
\hline Good allograft function & 4 & 5 & 4 \\
Chronic impairment of function & 1 & 3 & 4 \\
Nephrectomy & 1 & 1 & \\
Death of patient & & & \\
\hline
\end{tabular}
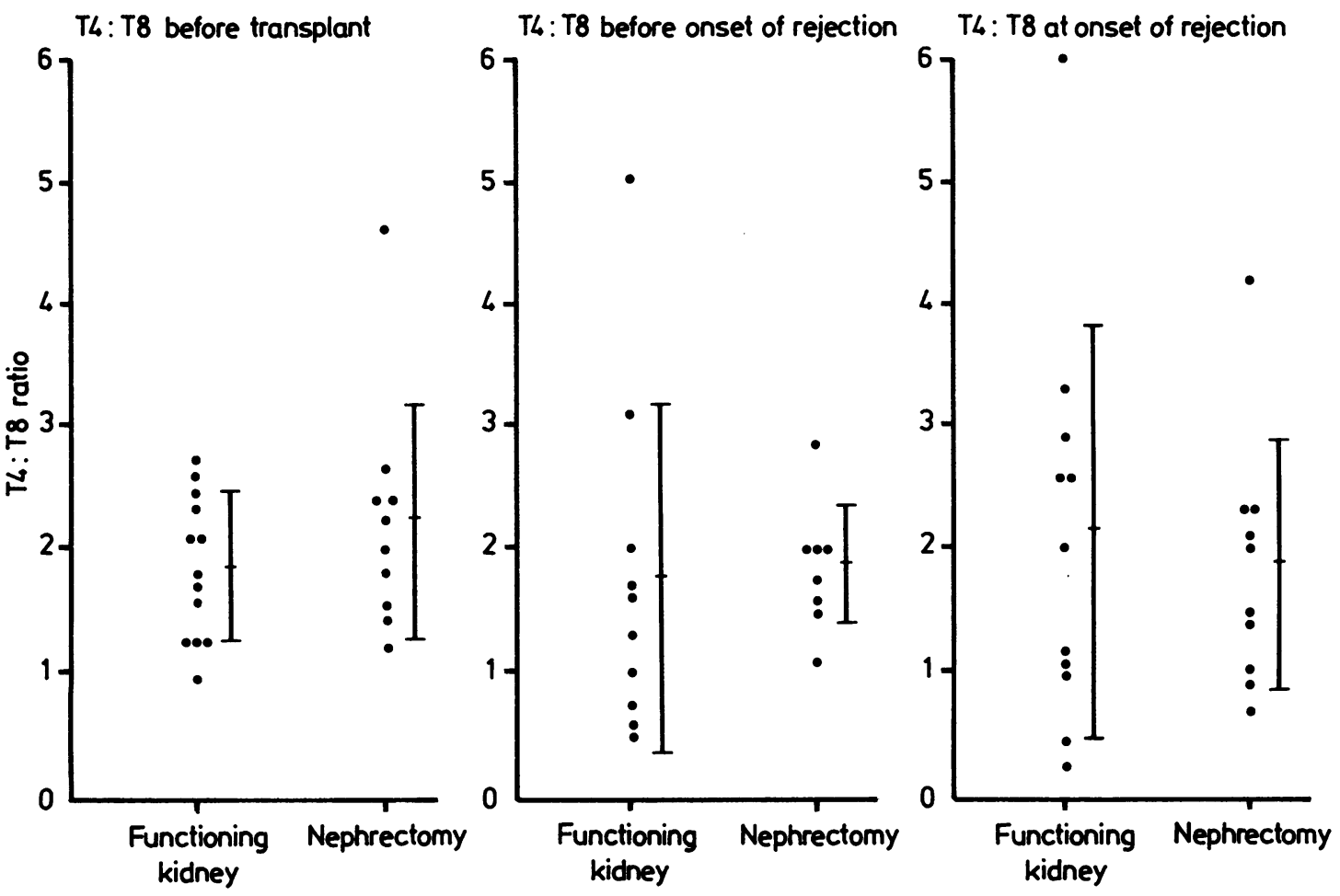

Fig. 4 Ratio of T4:T8 v outcome of transplant.

\section{Discussion}

This study was confined to those patients undergoing rejection episodes in the early post-transplant period for whom histological documentation of rejection was available. Previous studies concerning $T$ cell subset monitoring have used clinical criteria for the diagnosis of rejection episodes but histological confirmation was not always available..$^{69-1216}$

We were unable to find any correlation between circulating $\mathrm{T}$ cell subset ratios and the occurrence of histologically proved rejection; in addition, no consistent relation between subset data and the vascular and tubulointerstitial components of rejection was apparent when these variables were considered separately.
Several authors have claimed that the T4:T8 ratio rises during rejection episodes ${ }^{6-9} 17$ or increases before rejection, or both. ${ }^{716}$ In contrast, others have found the ratio to be unchanged during rejection. ${ }^{10-13}$ Claims have been made that this ratio predicts the occurrence of rejection ${ }^{616}$ or its reversibility $^{16}$ and pretransplant ratios may even predict ultimate graft loss from rejection. ${ }^{13}{ }^{16}$ These assertions have not been confirmed by other centres. ${ }^{91112}$ It has been suggested that such inconsistency may be due partly to the diversity of immunosuppressive regimens used by different centres. ${ }^{12}$ In our experience with conventional immunosuppression the $T$ cell subset ratios fluctuated widely both within patients and between different patients, irrespective of clinical events in the post-transplant period. 
Neither absolute numbers nor $\mathrm{T}$ cell ratios could be correlated with rejection in any way.

Characterisation of mononuclear cells infiltrating the renal tissue within rejecting allografts has consistently shown a high proportion of suppressor/ cytotoxic (T8 positive) cells, with an inverse ratio of T4: T8 relative to that present in the circulation. ${ }^{18-20}$ Again, however, there is lack of agreement over the correlation of $T$ cell status within the graft with the severity or reversibility of rejection. It is not known whether the population of T8 positive cells in the graft consists predominantly of cytotoxic or suppressor cells, nor do we know if these are the same as the T8 positive lymphocyte population in the peripheral blood. There seems, therefore, to be no reason to expect the peripheral blood subsets to mirror events occurring within the rejecting graft. Histological appearances reflect the degree of renal damage resulting from the sum of various immunological mechanisms operating during rejection, of which the T4: T8 ratio is at best merely one variable.

No information is available regarding the histological changes occurring in the allograft during the evolution of a rejection episode, especially with regard to the influence of treatment on these appearances. Our studies suggest that the severity of rejection remains constant during a given episode and that the histological appearance is unaffected by concurrent antirejection steroid treatment.

We conclude that renal biopsy remains the best method for determining allograft rejection and is efficient in predicting graft survival. The significance of the histological features appears to be unaffected by the timing of the biopsy or the concurrent treatment of the rejection episode. Conversely, we have found peripheral blood $T$ cell monitoring a time consuming and highly expensive exercise which has not aided clinical management.

We thank Mrs C Ramsden for technical help and Miss M Walkington for secretarial help.

\section{References}

' Matas AJ, Sibley R, Mauer M, Sutherland DER, Simmons RL, Najarian JS. The value of needle renal allograft biopsy; 1 . A retrospective study of biopsies performed during putative rejection episodes. Ann Surg 1983;197:226-37.

2 Magil A, Rubin J, Ladewig L, Johnson M, Goldstein MB, Bear RA. Renal biopsy in acute allograft rejection. Nephron 1980;26: 180-3.
'Herbertson BM, Evans DB, Calne RY, Banerjee AK. Percutaneous needle biopsies of renal allografts: the relationship between morphological changes present in biopsies and subsequent allograft function. Histopathology 1977;1:161-78.

${ }^{4}$ Finkelstein FO, Siegel NJ, Bastl C, Forrest JN, Kashgarian M. Kidney transplant biopsies in the diagnosis and management of acute rejection reactions. Kidney Int 1976;10:171-8.

s Tursz T, Fournier C, Kreis H, Crosnier J, Bach JF. T lymphocytes in kidney allograft recipients. Br Med J 1976;i:799-801.

- Cosimi AB, Colvin RB, Burton RC, et al. Use of monoclonal antibodies to $\mathrm{T}$ cell subsets for immunologic monitoring and treatment in recipients of renal allografts. $N$ Engl $J$ Med 1981;305:308-14.

Ellis TM. Berry CR, Mendez-Picon G, et al. Immunological monitoring of renal allograft recipients using monoclonal antibodies to human $\mathrm{T}$ lymphocyte subpopulations. Transplantation 1982:33:317-9.

* Ellis TM, Lee HM, Mohanakumar T. Alterations in human regulatory $T$ lymphocyte subpopulations after renal allografting. $J$ Immunol 1981;127:2199-203.

' Chatenoud L, Chkoff N, Kreis H, Bach JF. Interest in and limitations of monoclonal anti-T-cell antibodies for the follow-up of renal transplant patients. Transplantation 1983;36:45-50.

"' Liebert M, Rosenthal JT, Merrall E, et al. Peripheral blood T lymphocytes found in renal allograft recipients treated with Cyclosporine. Transplantation 1983;36:200-2.

" Fiche M, Soulillou JP, Bignon JD, Billaudel S, Guenel J. T lymphocyte monitoring in kidney transplant recipients undergoing cytomegalovirus infection or rejection episodes. Transplantation 1984;37:421-3.

1: Morris PJ, Carter NP, Cullen PR, Thompson JF, Wood RFM. Role of $\mathrm{T}$ cell subset monitoring in renal allograft recipients (letter). N Engl J Med 1982;306:1110-1.

"Van Es A, Tanke HJ, Baldwin WM, Oljans PJ, Ploem JS, Van Es LA. Ratios of T lymphocyte subpopulations predict survival of cadaveric renal allografts in adult patients on low dose corticosteroid therapy. Clin Exp Immunol 1983;52:13-20.

is Guillou PJ, Hegarty J, Ramsden C, Davison AM, Will EJ, Giles GR. Changes in human natural killer activity early and late after renal transplantation using conventional immunosuppression. Transplantation 1982;33:414-21.

is Guillou PJ, Will EJ, Davison AM, Giles GR. CAPD-a risk factor in renal transplantation? Br J Surg 1984;71:878-80.

10 Stelzer GT, McLeish KR, Lorden RE, Watson SL. Alterations in $T$ lymphocyte subpopulations associated with renal allograft rejection. Transplantation 1984;37:261-4.

17 Mazaheri R, Lau-pacis A, Keown P, Howson W, Sinclair NR, Stiller CR. Lymphocyte subsets in the allograft recipient: correlation of helper to suppressor ratio with clinical events. Transplant Proc 1982; 14:676-8.

${ }^{18}$ Platt JL, LeBien TW, Michael AF. Interstitial mononuclear cell populations in renal graft rejection. J Exp Med 1982;155:1730.

14 Van Es A, Meyer CJLM, Oljans PJ, Tanke HJ, Van Es LA. Mononuclear cells in renal allografts. Transplantation 1984;37:134-9.

2" Hancock WW, Thomson NM, Atkins RC. Composition of interstitial cellular infiltrate identified by monoclonal antibodies in renal biopsies of rejecting human renal allografts. Transplantation 1983;35:458-63.

Requests for reprints to: Dr SR Aparicio, Electron Microscopy Unit, Clinical Sciences Building, St James's University Hospital, Beckett Street, Leeds 9. 